\title{
Effects of Solar Activity and Stratospheric QBO on Tropical Monsoon Rainfall
}

\author{
K. MOHANAKUMAR \\ Department of Atmospheric Sciences, Cochin University of Science and Technology, Cochin 682 016, India
}

(Received December 7, 1994; Revised October 14, 1995; Accepted November 8, 1995)

\begin{abstract}
A study on the influence of solar activity and phases of equatorial quasi-biennial oscillation (QBO) on tropical rainfall over India has been made. The results of the total rainfall over the country indicate that during the period of low solar activity, excess/normal rainfall (frequent floods) are associated with the westerly phase of QBO and deficient/normal rainfall (frequent droughts) corresponded to the easterly phase. During the period of high solar activity only normal rain is observed when QBO is in its westerly phase. Multiple regression analysis has employed to estimate the summer monsoon rainfall using sunspot number and equatorial zonal wind at $15-20 \mathrm{hPa}$ during January-February as independent parameters. A study on the spatial variability of monsoon rainfall in response to the solar activity and phases of QBO has also been attempted.
\end{abstract}

\section{Introduction}

Sun-weather/climate relationship has been an active ficld of investigation for more than a century. Since the Sun is the primary source of energy for terrestrial weather processes, it is natural to enquire whether the observed variability of weather and climate can be linked with changes in solar activity. The possibility of finding clues for long range weather prediction has provided the motivation for some of the recent investigations.

Awareness of the need to understand and predict the monsoon have recently generated much interest in the possible relationships between the amount and distribution of monsoon rainfall and antecedent regional and global features. The southwest monsoon gives 75 to 90 per cent of the annual rainfall of India during the period June to September. Despite the regular nature of the monsoon rainfall, it exhibits considerable year-to-year variability. The floods and droughts that occur during the monsoon season due to excess or deficient rainfall associated with certain types of synoptic situations. The most important need in monsoon forecasting is to pick out, with a reasonable degree of success, the years of excess and deficient rainfall (Mooley and Parthasarathy, 1983).

The discovery of QBO in the tropical stratospheric winds stimulated the search for stratospherictropospheric links. Earlier studies by Raja Rao and Lakhole (1978), Mukherjee et al. (1985) and Bhalme et al. (1987) showed evidence for a link between the Indian monsoon and stratospheric zonal winds. A dominant QBO spectral peak in the Indian summer monsoon rainfall and the number of monsoon depressions was also reported (Bhalme and Jadhav, 1984). Yasunari (1989) studied the link of the QBOs between the stratosphere, troposphere and sea surface temperature in the tropics. His results suggested a possible dynamical link of the QBO in the large-scale coupled atmosphere/ocean system over the Asian monsoon region through the equatorial Pacific with in the equatorial stratosphere. Detailed studies on the relation between Indian rainfall and sunspot cycle have also been made by Ananthakrishnan and Parthasarathy (1984) based on data for a period of 109 years.

The interesting finding by Labitzke (1987) inspired us to look for a possible connection between the Solar-QBO effect and the tropical rainfall over India. Preliminary studies on the influence of solar activity and the phases of the equatorial QBO on the rainfall have been attempted (Mohanakumar and Labitzke, 1991). Previous studies, mentioned in this paper, either looked for a connection between the solar activity and rainfall or between the QBO and rainfall. In the present study, we investigated the combined effect 
of both solar activity and phase as well as the speed of the equatorial QBO on annual and monsoon rainfall over the Indian subcontinent.

\section{Data and Analysis}

The rainfall and sunspot number data are available for more than a century. But the equatorial lower stratospheric zonal wind (QBO) data are available only from 1953 onwards. The present analysis is, therefore, limited to 42 years of data obtained from 1953 to 1994 . The updated zonal wind data used in this study is available at the Stratospheric Research Group, Freie Universität Berlin.

Recent studies (Labitzke, 1987; Labitzke and Van Loon, 1988, 1992; Van Loon and Labitzke, 1990; Venne and Dartt, 1990, etc.) showed that the QBO of zonal wind in 40-50 hPa level plays a major role in the connection between solar activity and tropospheric weather. It is well known that the phases of equatorial QBO propagate downwards in the lower stratosphere at the rate of $\sim 1 \mathrm{~km} / \mathrm{month}$ and it disappears in the tropical tropopause region. The active rainfall season over India is during the monsoon season from June to September, and gives about $80 \%$ of the annual rainfall. To give a forecast well before the onset of monsoon, we considered the zonal wind data at the 15-20 hPa level during January and February and at the $40-50 \mathrm{hPa}$ level during June to September. It is found that $95 \%$ cases the phases are the same and in other cases even though the phases are opposite they are weak and in the transition stage. Therefore, we decided to use the January-February zonal wind data at the $15-20 \mathrm{hPa}$ level for the forecast of the monsoon activity which occur during the period June to September.

Since sunspot number do not show much variations in a year and considering the importance of giving a forecast of monsoon rainfall in the earlier part of the year itself, we took January-February sunspot number as the solar activity parameter corresponding to the period considered for QBO in $15-20 \mathrm{hPa}$ level. It is also to be noted that during this period the position of the Earth is closer to the Sun, so a stronger influence of the solar activity can be expected on the Earth's atmosphere. Sunspot number data used in the present study have been obtained from the Solar Geophysical Data, published by World Data CenterA, Boulder, Colorado. The solar activity is taken as "low" when the sunspot number is less than the mean of the series (77) and as "high" when the sunspot number is above the mean.

The rainfall data for the present study is the annual as well as southwest monsoon (June to September) rainfall over the entire Indian region, published by the India Meteorological Department (IMD) based on observations taken from its various meteorological observatories throughout the country. The rainfall is classified as excess, normal and deficient according to the standard definition adopted by the World Meteorological Organisation (WMO). According to this classification when the percentage departure of rainfall is within $+/-10$ percent of the long period mean, it is denoted as "Normal". When the percentage departure exceeds 10 percent it is termed as "Excess" or Flood year and less than 10 per cent it is called as "Deficient" or Drought year.

\section{Results}

\subsection{Solar-QBO effect on annual rainfall over the entire India}

The rainfall years are divided into four categories according to the definitions mentioned above. They are, (1) low solar activity-West QBO, (2) low solar activity-East QBO, (3) high solar activity-West QBO and (4) high solar activity-East QBO. The actual number of occurrences of normal, excess and deficient rainfall years in each category are indicated in the pie charts as shown in Fig. 1. To illustrate Fig. 1, the yearly distribution of the departure of annual rainfall from the long period mean with the solar activity and phases of QBO are given in Table 1.

It can be seen that during the period of low solar activity, excess rainfall is associated with the westerly phase of QBO and deficient rainfall is connected with the easterly phase. Normal rainfall is evenly distributed in the two phases of QBO during solar minimum period. Out of the 10 westerly phases during this period, 6 of them lead to severe flood in the country and no drought occurred. On the other hand, 

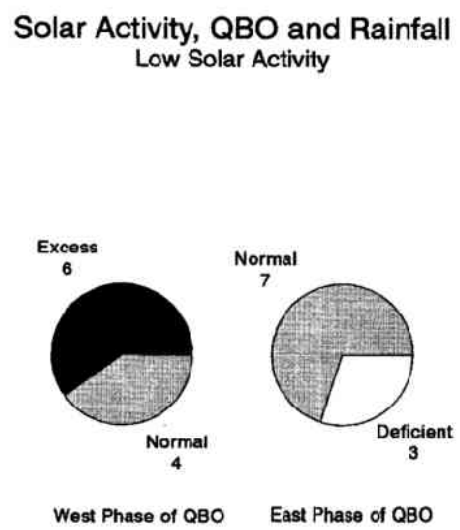

High Solar Activity

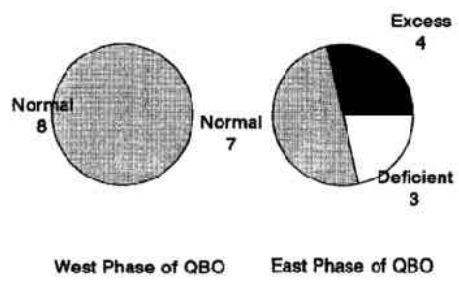

Fig. 1. Pie charts illustrating the number of occurrence of deficient, excess and normal rainfall associated with phases of $Q B O$ and solar activity.

in the easterly phase of QBO, about one-third of its appearance caused droughts and none gave excess rainfall. This shows that when the solar activity is low and the zonal wind at the $15-20 \mathrm{hPa}$ level during January-February is westerly, excess/normal rainfall results and the possibility of flood can be expected. On the other hand, when the QBO is in its easterly phase during this period, deficient/normal rainfall occurs and the chance of drought can be anticipated.

During the period of high solar activity and when the QBO is in its westerly phase, only normal rainfall is observed. All the 8 westerly phases of QBO during solar maximum considered for the study, showed normal rainfall without much deviation from its annual mean value. There was no drought or flood reported during this period. But in the easterly phase of QBO during high solar activity, the picture is not clear. All the three possibilities can occur in this phase and make the forecasting difficult. One can expect either drought or flood in the coming year during the easterly phase.

\subsection{Monsoon rainfall variability and $Q B O$ phase}

Summer monsoon rainfall during the four months (June-September) over the Indian sub-continent from 1953 to 1994 are shown in Fig. 2. The phase of equatorial QBO of zonal wind at $15-20 \mathrm{hPa}$ level during the month of January and February in each year is indicated as $\mathrm{E}$ (for easterly) and W (for westerly). 
Table 1. Classification of annual rainfall departure according to the phases of QBO and solar activity.

\begin{tabular}{|c|c|c|c|c|c|c|}
\hline \multirow[t]{2}{*}{ QBO phase } & \multicolumn{3}{|c|}{ Low solar activity $(\mathrm{SS}<77)$} & \multicolumn{3}{|c|}{ High solar activity $(\mathrm{SS}>77)$} \\
\hline & $\begin{array}{l}\text { Excess } \\
(>10 \%)\end{array}$ & $\begin{array}{c}\text { Normal } \\
(+i-10 \%)\end{array}$ & $\begin{array}{c}\text { Deficient } \\
(<10 \%)\end{array}$ & $\begin{array}{l}\text { Excess } \\
(>10 \%)\end{array}$ & $\begin{array}{c}\text { Normal } \\
(+/-10 \%)\end{array}$ & $\begin{array}{c}\text { Deficient } \\
(<10 \%)\end{array}$ \\
\hline \multirow[t]{8}{*}{ West } & $1955(+11)$ & $1953(+9)$ & - & - & $1957(+3)$ & - \\
\hline & $1961(+24)$ & $1966(-9)$ & - & - & $1967(-0)$ & - \\
\hline & $1973(+22)$ & $1976(+7)$ & - & - & $1969(-3)$ & - \\
\hline & $1975(+18)$ & $1985(-5)$ & - & - & $1971(+2)$ & - \\
\hline & $1983(+17)$ & - & - & - & $1978(+8)$ & - \\
\hline & $1988(+19)$ & - & - & - & $1980(+5)$ & - \\
\hline & - & - & - & - & $1990(+6)$ & - \\
\hline & - & - & - & - & $1993(+2)$ & - \\
\hline \multirow[t]{7}{*}{ East } & - & $1954(0)$ & $1965(-17)$ & $1956(+13)$ & $1960(+3)$ & $1972(-20)$ \\
\hline & - & $1962(+3)$ & $1986(-12)$ & $1958(+11)$ & $1968(-8)$ & $1979(-16)$ \\
\hline & - & $1963(-2)$ & $1987(-16)$ & $1959(+14)$ & $1981(+2)$ & $1982(-12)$ \\
\hline & - & $1964(+8)$ & - & $1970(+11)$ & $1984(-2)$ & - \\
\hline & - & $1974(-8)$ & - & - & $1989(+7)$ & - \\
\hline & - & $1977(+5)$ & - & - & $1991(-4)$ & - \\
\hline & - & $1994(-1)$ & - & - & $1992(-5)$ & - \\
\hline
\end{tabular}

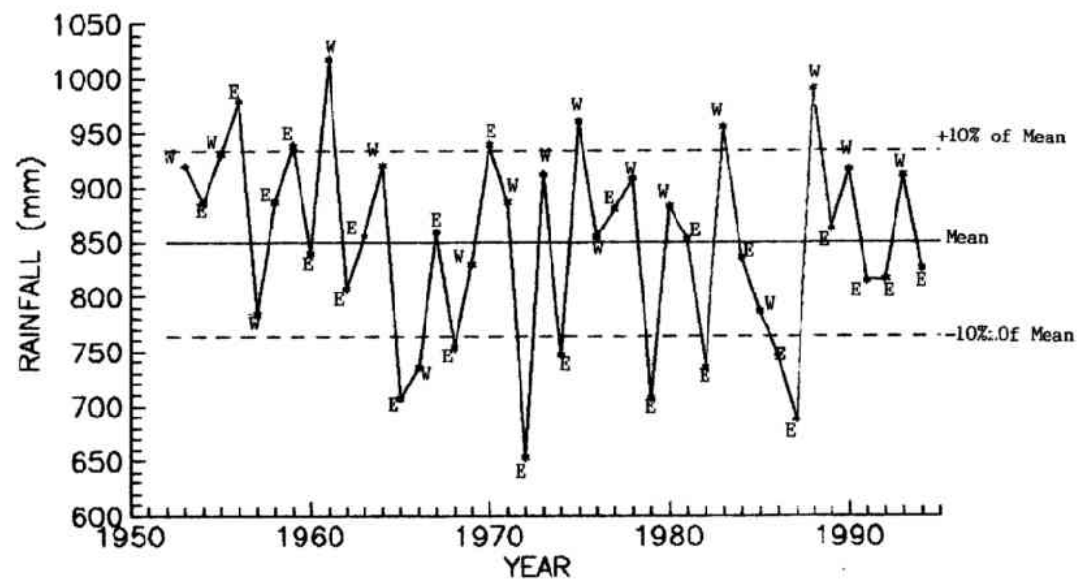

Fig. 2. Year-to-year variations in monsoon rainfall and phases of QBO.

The mean as well as good (above $10 \%$ departure from long period mean) and bad (below $10 \%$ departure from the mean) monsoon rainfall amounts are also marked in Fig. 2. Above normal monsoon rainfall years are generally associated during the westerly phase of $\mathrm{QBO}$ and below normal monsoon rainfall years are normally noted during the east phase. Out of the 42 years of monsoon rainfall considered for the study, 25 normal rainfall years are noted, in which easterly and westerly phases are 13 and 12 , respectively. There are 8 good monsoon rainfall years are found with 5 westerly and 3 easterly phases of QBO. Bad monsoon years are clearly associated with the easterly phase of QBO. Nine bad monsoon years are observed during the last 42 years, in which 8 of them occurred during the easterly phase and only one instance occurred during the westerly phase. 


\subsection{Multiple regression analysis}

The study is further extended to find a statistical association between the combined effect of solar activity-QBO and monsoon rainfall. The correlation coefficient computed between the monsoon rainfall and sunspot number is found to be very low and insignificant $(r=0.0356)$. But there exist a positive and significant correlation $(r=0.4523)$ between the rainfall and the QBO, considering both the phase and speed of the equatorial lower stratospheric wind at 15-20 hPa level. Assuming that the combined effect of the solar and QBO activities are influencing the rainfall, the rainfall is estimated by using the multlple regression equation;

$$
R i(\mathrm{est})=\langle R\rangle+B(s, r) \times(S i-\langle S\rangle)+B(q, r) \times(Q i-\langle Q\rangle)
$$

where, $R i$ (est) is the estimated monsoon rainfall in $\mathrm{mm}, \angle R>$ is the average monsoon rainfall for the whole period $(849.5 \mathrm{~mm}), B(s, r)$ is the regression coefficient of rainfall on sunspot number $(0.0556 \mathrm{~mm}$ of rainfall/sunspotnumber), $S i$, is the sunspot number(January-February mean) in each year, $\langle S\rangle$ is the average value of the sunspot number (77), $B(q, r)$ is the regression coefficient of rainfall on QBO $(2.26 \mathrm{~mm}$ of rainfall/zonal wind in $\mathrm{cm} \cdot \mathrm{sec}^{-1}$ ), $Q i$ is the January-February equatorial zonal wind at $15-20 \mathrm{hPa}$ level and $\left\langle Q>\right.$ is the mean wind for the whole period $\left(-7.1 \mathrm{~cm} \cdot \mathrm{sec}^{-1}\right)$.

Using Eq. (1), the monsoon rainfall is predicted in each year combinedly with solar activity and QBO and is shown in Fig. 3 along with the observed values. Similarly the monsoon rainfall is computed considering the QBO effect alone. The predicted rainfall considering the combined effect of both the solar activity and QBO and the observed rainfall values gives a better correlation than that alone with the QBO or with the sunspot number separately. It can be seen that the combined effect of both solar activity and QBO predicts rather well when the rainfall is at the higher side of the mean. The lower rainfall years can be estimated relatively better when one consider the effect of both the phase as well as the speed of the stratospheric zonal wind without incorporating the solar activity. The correlation coefficient between the $R$ (obs) and the $R$ (est) is found to be 0.5414 , which is positive and highly significant ( $>99 \%$ level of significance with 41 degrees of freedom). The standard error of estimate is found to be 9.52 , which is relatively lower than that with sunspot number or with QBO independently.

\subsection{Combined effect of the Sun, QBO and ENSO on rainfall}

An attempt is further made to combine the El Nino Southern Oscillation (ENSO) along with the solar and QBO activities. Some of the earlier studies indicated that the ENSO has a strong connection with the

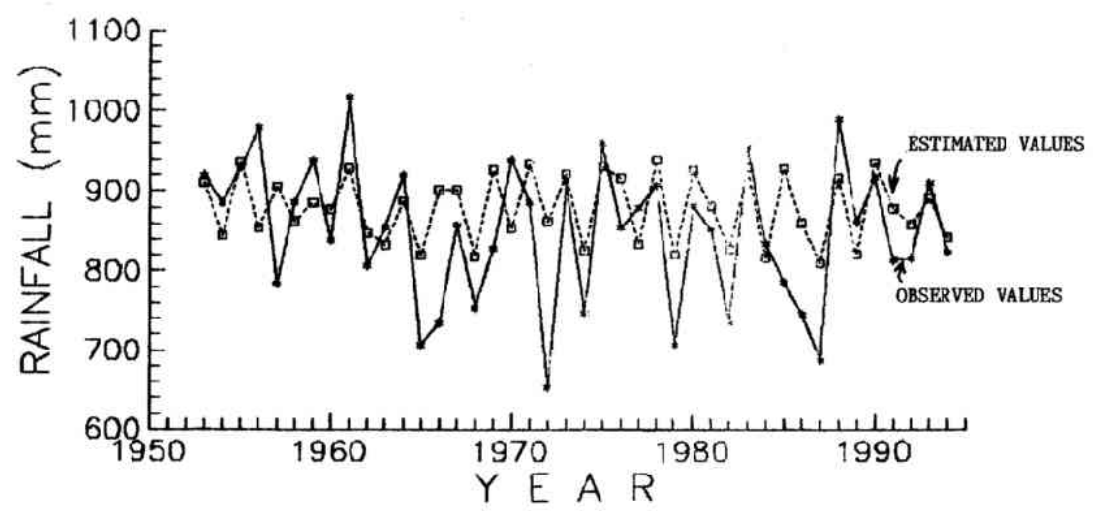

Fig. 3. Observed and estimated amounts of monsoon rainfall. 
rainfall over Indian region. The linear correlation coefficient between annual rainfall and the southern oscillation index during the months of January and February showed a negative and insignificant correlation (-0.2270). Incorporating the ENSO also into the multiple regression equation (Eq. (1)) and the rainfall is predicted. Thus predicted values does not show any considerable improvement in predicting the values after including the ENSO. The correlation coefficient between the observed and the predicted rainfall including the ENSO $(0.4256)$ does not change significantly from that without considering the ENSO effect. A better statistically significant correlation is thus exists between the combined effect of solar activity and the magnitude and phase of the QBO during the earlier part of the year and the monsoon rainfall over the Indian subcontinent.

Table 2. Regional classification of macro-meteorological divisions (Gregory, 1989).

\begin{tabular}{ccl}
\hline Region number & Subdivision number & \multicolumn{1}{c}{ Area description } \\
\hline 1 & 3 and 4 & Assam \\
2 & 5 and 9 & Northern West Bengal and Bihar \\
3 & 6 and 8 & Southern West Bengal and Bihar \\
4 & 7 and 20 & Northeast Peninsula \\
5 & 10 and 11 & Uttar Pradesh \\
6 & $13,14,17,18$ and 19 & North-west part \\
7 & 21 and 22 & Gujarat, Saurashtra and Kutch \\
8 & 23 to 24,28 and 32 & North-west and north-centre Peninsula \\
9 & 27,29 and 30 & South-east Peninsula \\
10 & 31,33 and 34 & South-west Peninsula \\
\hline
\end{tabular}

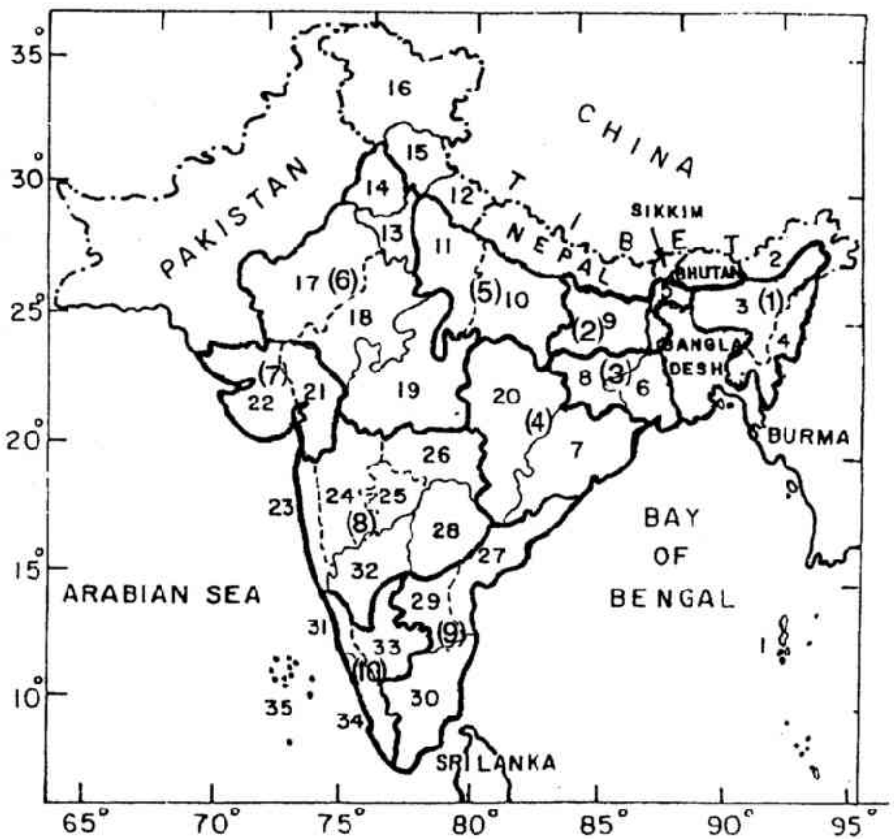

Fig. 4. Map showing the distribution of the meteorological divisions of India (macro-divisions are shown in thick lines and are indicated in brackets). 


\subsection{Spatial changes in monsoon rainfall associated with solar-QBO effect}

The regional distribution of the monsoon variability have also been studied in response to the changes in the activity of the Sun and phases of the equatorial QBO. The use of the average data set for the whole Indian region obscures the regional differences. There are 35 standard meteorological sub divisions are classified in the whole country. Several of these sub division may have similar features in terms of change over time (Mooley and Parthasarathy, 1983) and therefore, it is more convenient to use a limited number of macro-regions, fewer in number than the 35 sub divisions for the purpose of the long-term studies. In the present analysis we adopted the classification made by Gregory (1989). According to this classification, the meteorological sub-divisions of the whole Indian region is grouped into 10 macro regions (see Table 2), excluding divisions in the hilly terrain (Arunachal Pradesh, hills of west Uttar Pradesh, Himachal Pradesh, and Jammu and Kashmlr - sub divisions 2, 12, 15 and 16, respectively) and island stations (Andaman and Nicobar, Lakshadweep - sub divisions 1 and 35, respectively). These excluded sub-

(a) Low Solar Activity \& QBO West

Number of Occurrence

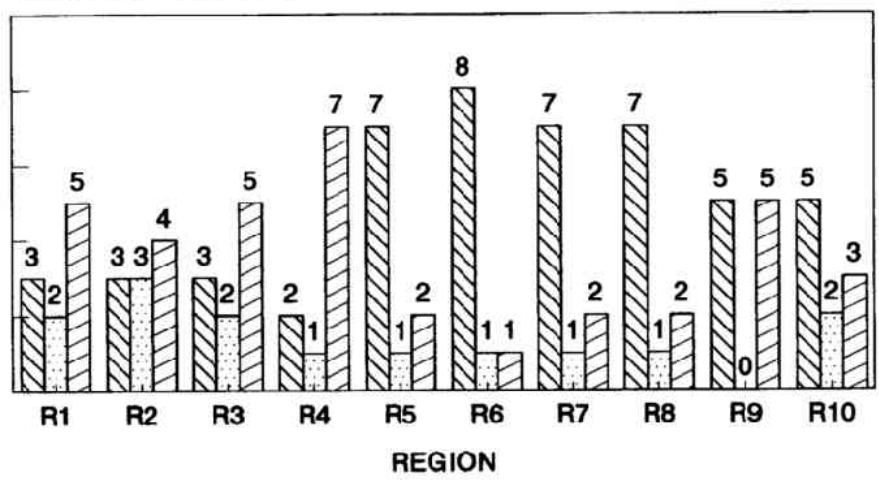

$\triangle$ Flood $\square$ Drought $\Xi_{\text {Normal }}$

\section{Low Solar Activity \& QBO East}

(b)

Number of Occurrence

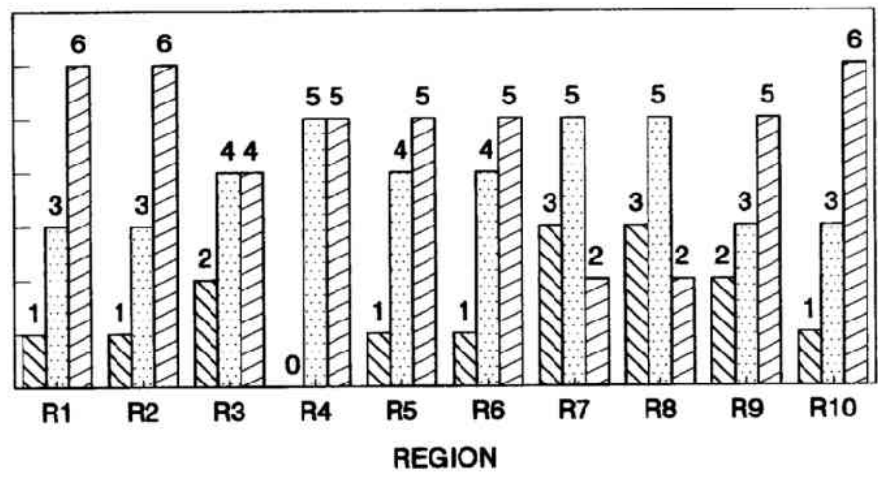

$\triangle$ Flood $⿴ 囗 0)$ Drought $\Xi_{\text {Normal }}$

Fig. 5. Spatial variability of the number of occurrence of flood, drought and normal rainfall conditions during low solar activity. 
divisions show relatively low coherency in climatic features compared to other meteorological divisions of the country. The map showing the distribution of the 10 macro meteorological regions is shown in Fig. 4.

The rainfall data for the 10 macro regions calculated from the four months (June to September)during the period 1953 to 1994 were used for the study. The sunspot number and the equatorial QBO at 15-20 $\mathrm{hPa}$ level during January and February months were used as the source parameters. For each region and for the four conditions (viz., low solar activity and west QBO, low solar activity and east QBO, high solar activity and west QBO and high solar activity and east QBO) the number of occurrence of flood/drought/ normal rainfall were analysed and are illustrated in Figs. 5 and 6 . A brief explanation of the common features noted in the four conditions are given as follows.

i. Low solar activity and west $Q B O$ : Normal rainfall is more frequent in the eastern part of India and the occurrence of flood is high in the central and north-western parts. In the southern part of the

(a) High Solar Activity \& QBO West

Number of Occurrence

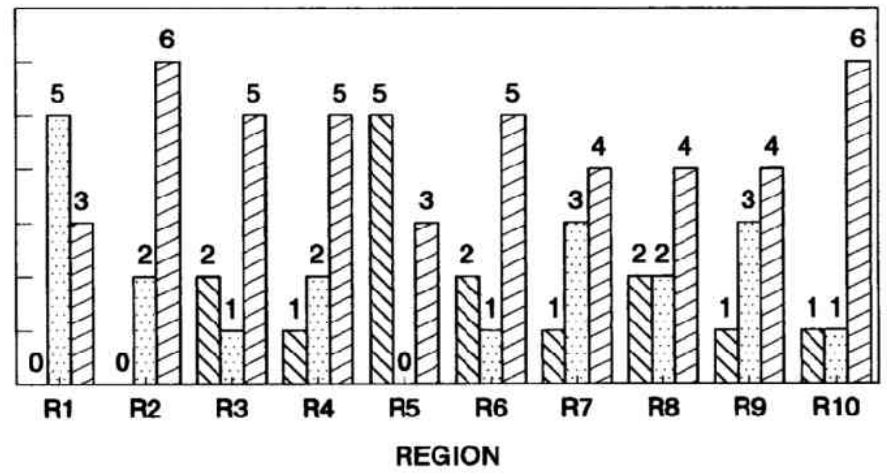

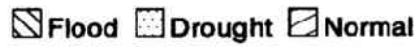

High Solar Activity \& QBO East

(b)

Number of Occurrence

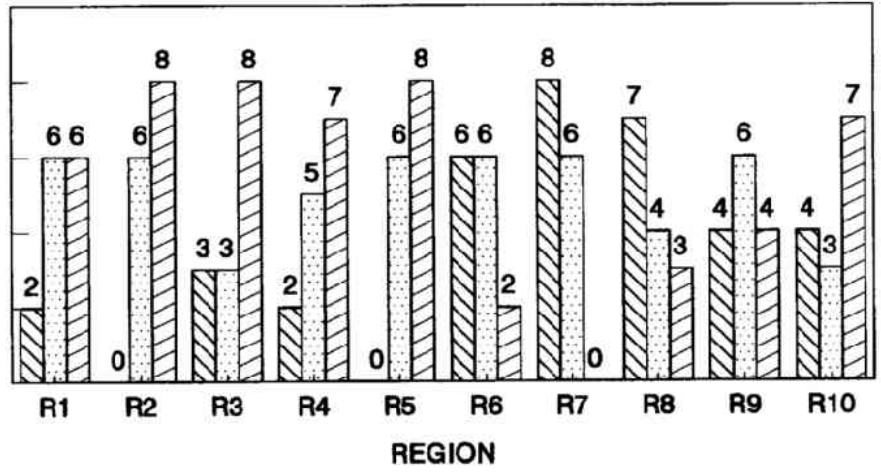

$\triangle$ Flood $⿴ 囗 0)$ Drought $\boxminus_{\text {Normal }}$

Fig. 6. Spatial variability of the number of occurrence of flood, drought and normal rainfall conditions during high solar activity. 
country, normal to excess rainfall is observed during this period (Fig. 5a).

ii. Low solar activity and east $Q B O$ : The monsoon is weak in the northeastern part of India. Low rainfall lead to drought conditions in most part of the country. Northwest part experienced relatively good monsoon. Normal rainfall is the common feature in the southern Peninsular region (see Fig. 5b).

iii. High solar activity and west $Q B O$ : High occurrence of drought is noted in the eastern part of the country. No excess rainfall is reported in these regions. The behaviour of monsoon in the central Indian region is just the reverse. The occurrence of flood is frequent and no drought occurred in this region. Northwest part of the country generally experienced normal rainfall. Normal rainfall is also observed in southwest peninsular region. Large variability in monsoon rainfall is noted in the southeast peninsular zone, where winter monsoon is predominant (Fig. 6a).

iv. High solar activity and east $Q B O$ : Deficient/normal rainfall is observed in the eastern part of India. The western part of the country experienced heavy rainfall and floods are frequent in regions 7 and 8. Drought is common in the south eastern peninsular region. During this period, normal rainfall is the common feature in the southwest Peninsular region (Fig. 6b).

\section{Discussion}

Recently, renewed attention is being given to the quasibiennial oscillation of zonal wind anomalies in the equatorial stratosphere as an active climate factor, affecting aspects of the extra-tropical stratosphere as well as the tropical troposphere and oceans. Shapiro (1989) have shown that the tropical convective activity enhances during the west phase of QBO and inhibits during the east phase. The results obtained by Yasunari (1989) suggest some plausible role of seasonal convective activity from summer through winter over the Asian monsoon region through the western Pacific on the QBO in the stratosphere. It is also mentioned that QBOs are strongly phase-locked to the seasonal cycle. Meehl (1987) presented a physical descriptive argument that suggests alternately strong and weak Indian summer monsoon may be related to tropospheric biennial variability. But the result obtained from the present study does not show an exact biennial variability in monsoon activity. Yasunari (1990) further suggested that part of the biennial southern oscillation variability may be a negative feedback between monsoon rainfall in one hand and sea surface temperature and salinity in the far western Pacific on the other.

Even though the above studies provided suggestions for investigation for understanding the relationship between QBO and monsoon rainfall, the mechanisms involved in the relationship between solar variability, the $\mathrm{QBO}$ and the weather and climate are not yet well understood.

\section{Conclusions}

The present study on the effects of both solar and QBO activity on tropical rainfall show that in the westerly phase of QBO, the occurrence of flood is high during solar minimum and only normal rainfall is observed during solar maximum. No droughts occurred when the QBO is in its westerly phase. Easterly phases of the QBO are generally associated with severe droughts during both solar minimum and maximum years. The floods are confined to the period of solar maximum. The ENSO effect is found to be relatively less influenced compared to QBO on the monsoon rainfall.

During the period of low solar activity and the westerly phase of the QBO, frequent floods are occurred in the northeast part of India and frequent droughts in the central Peninsular region. In the easterly phase, during this period, the monsoon is weak in the northeast and is active in the western coastal part of the country. Associated with the period of high solar activity and westerly phase of the QBO, deficient rainfall is noted in the eastern region and experienced very good rainfall in the central India. Significance of the study: If the phase of the equatorial zonal wind at the 15-20 hPa level during the months of JanuaryFebruary are observed and by knowing the activity of the Sun during this period, the present finding may have some implications for the long range forecasting of the occurrence or the non-occurrence of the extreme climatic events such as drought/flood in the rest of the year which have an important value to the 
agriculture and the economy of the country (India). However, the study is limited to the data based on 42 years (1953-1994), and at present it is not possible to extend further, because of the unavailability of the QBO data prior to 1953. The number of data samples in different cases are not too large to test statistically.

The author wish to express his sincere thanks to Professor Dr. Karin Labitzke, Institut für Meteorologie, Freie Universität Berlin, FRG, for the useful discussion on the above topic and her constant encouragement. The financial support given by the Commission of the European Communities (CEC) through the post doctoral research fellowship is also acknowledged.

\section{REFERENCES}

Ananthakrishnan, R. and B. Parthasarathy, Indian rainfall in relation to the sunspot cycle:1871-1978, J. Climatol., 4, 149-169, 1984.

Bhalme, H. N. and S. K. Jadhav, The southern oscillation and its relation to the monsoon rainfall, J. Climatol., 4, 509-520, 1984.

Bhalme, H. N., S. S. Rahalkar, and A. B. Sikder, Tropical quasibiennial oscillation of the 10-mb wind and Indian summer monsoon rainfall-Implications for forecasting, J. Climatol., 7, 345-353, 1987.

Gregory, S. Macro-regional definition and characteristics of Indian summer monsoon rainfall, 1871-1985, Internatnl. J. Climatol., 9, 465-483, 1989.

Labitzke, K., Sunspots, the QBO, and the stratospheric temperature in the north polar region, Geophys. Res. Lett., 14, 535-537, 1987.

Labitzke, K. and H. Van Loon, Associations between the 11-year solar cycle, the QBO and the atmosphere, Part I, The troposphere and stratosphere in the northern hemisphere in winter, J. Atmos. Terr. Phys., 50, 197-206, 1988.

Labitzke, K. and H. Van Loon, Associations between the 11-year solar cycle, the QBO and the atmosphere, Part V, Summer, J. Climatol., 5, 240-251, 1992.

Meehl, G. A., The annual cycle and interannual variability in the tropical Pacific and Indian Ocean regions, Mon. Wea. Rev., 115, 27-50, 1987.

Mohanakumar, K. and K. Labitzke, Solar-QBO effect on tropical rainfall, abstracted in Ann. Geophys. 9, $276,1991$.

Mooley, D. A. and B. Parthasarathy, Variability of Indian summer monsoon and tropical circulation features, Mon. Wea. Rev., 111, 967-978, 1983.

Mukherjee, B. K., K. Indira, R. S. Reddy, and Bh. V. Ramana Murty, Quasi-biennial oscillation in stratospheric zonal wind and Indian summer monsoon, Mon. Wea. Rev., 113, 1421-1429, 1985.

Raja Rao, K. S. and N. J. Lakhole, Quasi-biennial oscillation and summer southwest monsoon, Indian J. Met. Hydrol. Geophys., 29, 403-412, 1978.

Shapiro, L., The relationships of the quasi-biennial oscillations to Atlantic tropical storm activity, Mon. Wea. Rev., 117, 15451552, 1989.

Van Loon, H. and K. Labitzke, Association between the 11-year solar cycle and atmosphere, IV. The stratosphere, not grouped by the phase of the QBO, J. Climatol., 3, 827-837, 1990.

Venne, D. F. and D. G. Dartt, An examination of possible solar cycle- QBO effects in the northern hemisphere troposphere, J. Climatol., 3, 272-281, 1990.

Yasunari, T., A possible link of the QBOs between the stratosphere, troposphere and sea surface temperature in the tropics, $J$. Met. Soc. Japan, 67, 483-493, 1989.

Yasunari, T., Monsoon andENSO-A coupledocean/land/atmosphere system, Proc. Int. TOGA Scientific Conf., Honolulu, World Meteorological Organisation, WCRP-43, WMO/TD No. 379, 111, 1990. 